\title{
Immigration enhances fast growth of a newly established source population
}

\author{
Simone Santoro, ${ }^{1}$ Andy J. Green, and Jordi Figuerola \\ Estación Biológica de Doñana (EBD-CSIC), Avenida Américo Vespucio S/N, Isla de la Cartuja, Sevilla 41092 Spain
}

\begin{abstract}
Immigration and local recruitment play a central role in determining the growth rate of breeding populations. Unraveling these processes in newly established populations is of great importance to increase our understanding of how species change their distributions in response to global change. We studied the largest colony of glossy ibis (Plegadis falcinellus) in Western Europe (established in 1996 in Doñana, SW-Spain) by using capture-recapture methods, count estimates, and projection matrix modeling to: (1) test the effect of resource availability and competition on local recruitment dynamics, (2) investigate the contribution of local recruitment vs. immigration on population growth, and (3) assess the role of this population in source/sink dynamics. We found different dynamics before and after the establishment of satellite colonies in Doñana in 2004. Between 1996 and 2003 , the population increased rapidly, fueled by immigrants $(\approx 58$ breeding females/ yr). Between 2003 and 2007, however, both colony size increase and immigration were negligible. Immigration played a major role in colony growth, but simultaneously this colony was a source population driving expansion of the species range as suggested by (1) absolute and relative estimates of the observed growth rate relative to that predicted by self-recruitment, and (2) numerous observations of Doñana-born individuals breeding elsewhere. Local recruitment, which was particularly high for first-year individuals (probability $>0.8$ for the early study years), was not directly related to resource availability or previous-year breeding success. Local recruitment decreased rapidly at a threshold population size, however, when other satellite colonies became established at Doñana. Our study suggests that even when recruitment at an early age and high productivity are observed, immigration can still play a pivotal role in promoting the fast growth of new populations at the edge of a species range, at least until density-dependent effects arise. This process can be so fast that within a few years a new population can itself become a source population, further driving range expansion of the species.
\end{abstract}

Key words: apparent survival; colonization; Leslie matrix; local survival; metapopulation; new colony; population dynamics.

\section{INTRODUCTION}

The distribution of many species of birds and other organisms is undergoing rapid change in response to human activities (Le Galliard et al. 2012). These changes in distribution reflect processes at individual and population levels that are usually poorly understood and hard to study. Environmental and genetic constraints regulate life-history traits and ultimately population size (Stearns 1992) mostly through variation in (1) survival, (2) age at first reproduction, and (3) number of fledglings per pair. These parameters can be estimated and used in matrix models (Van Groenendael et al. 1988) to estimate the contribution of local recruitment to the growth of breeding populations (e.g., Doxa et al. 2013), which also depends on immigration/emigration. Within a metapopulation in which individual populations are linked by

Manuscript received 25 December 2014; revised 14 August 2015; accepted 28 September 2015. Corresponding Editor: J. R. Sauer.

'E-mail: santoro@ebd.csic.es dispersal, the recruitment and growth rates of a specific population determine its source-sink dynamics and therefore affect metapopulation dynamics and species distribution (Hanski 1998). It is particularly important to investigate the mechanisms underlying variation in life-histories and ultimately population dynamics at range limits where peripheral populations may be promoting the geographical expansion or contraction of a species (Gaston 2009).

The rate at which new breeders recruit can be affected by numerous factors that may be biotic or abiotic, intrinsic or extrinsic. For instance, the "conspecific attraction hypothesis" (CAH) (Stamps 1988) posits that local population size can be used by potential recruits as a proxy for environmental conditions and therefore influence their settlement decision (see Oro and Pradel 2000). Instead of the mere presence of conspecifics, their reproductive success can be used to assess the suitability of a site for recruiting (Danchin et al. 1998). We refer to this as the "reproductive success hypothesis" (RSH). A number of other factors related to the extent of 
competition may also affect recruitment, and the "food availability hypothesis" (FAH) refers to one of these (Porter and Coulson 1987).

Life-history theory posits that the age at first reproduction varies according to the tradeoff between related benefits and costs, in terms of survival and future reproduction (Stearns 1992). Survival and reproductive performance tend to increase with age (Forslund and Pärt 1995), with the specific form of this relationship determining the optimal age at first reproduction. There is a well-established positive relationship between longevity and age at first reproduction in birds (Møller 2006), but factors such as habitat heterogeneity and population density might override this general rule.

The glossy ibis is a semi-cosmopolitan long-lived bird species (Newton 2003) whose population dynamics and demographic parameters are little known (but see Davis and Kricher 2000, Santoro et al. 2013 and references therein). Following the creation of a managed wetland within Doñana in SW Spain, a mixed colony (with several heron species) was established in 1996 with only seven pairs of glossy ibis, whose breeding population has increased steeply since then (Santoro et al. 2010, Ramo et al. 2013).

In this study, we investigated the demographic processes that regulate the expansion of a species by long-term monitoring of the glossy ibis breeding population at Doñana. First, we evaluated the effects of intrinsic and extrinsic factors on the local survival and recruitment. We calculated the age of first reproduction for both sexes, and tested the hypothesis that local survival depends on both age and sex. We also tested the hypotheses that local recruitment would be positively correlated with breeding success the previous year (Reproductive Success Hypothesis), resource availability in feeding grounds (Food Availability Hypothesis), and the size of the colony (Conspecific Attraction Hypothesis), bearing in mind that we could not evaluate tradeoffs between these hypotheses. Second, we investigated the influence of local recruitment vs. immigration on growth of the breeding population, at the same time using this information to assess the source-sink nature of the study population. Finally, we described the recent range expansion of glossy ibis based on resightings of individuals hatched at Doñana. We reveal a particularly strong contribution of one colony to the geographical expansion of a species, which has rarely been reported in any bird.

\section{Methods \\ Study area, colony site, and field data}

Doñana is a large protected wetland area covering 108,087 ha (details in Ramo et al. 2013). After being extinct in Doñana for many decades, in 1996 seven breeding pairs of glossy ibis settled in a pond-system (50 ha) known as "Lucio de la FAO" (FAO hereon) (Santoro et al. 2010, 2013). Strong population growth followed, with more than 7,000 breeding pairs estimated in 2011 in the whole of Doñana. After an initial period (1996-2003) when they only bred at the FAO colony, ibis started to breed in satellite colonies within the Doñana marshes. Over the last $20 \mathrm{yr}$, other smaller breeding colonies have established in East (1993) and Northeast Spain (1996) (Mañez and Rendón-Martos 2009), in the Camargue, France (2006) (Kayser et al. 2009), Argelia (1998) (Boucheker et al. 2009), Southwest (1994), and North(2011) Morocco(Amezian etal.2012). Additionally, irregular breeding has occurred in Portugal (Noivo and Jara 2007), Italy (Brichetti 1986, Grussu 2004), and some other areas in Spain, France (Marion and Marion 2011) and Morocco, especially since 2005 when a severe drought prevented breeding in Doñana (Santoro et al. 2013; details in Table S1).

Since 1996, more than 16,000 ibis chicks have been marked in Doñana with darvic rings with an alphanumeric code (3-4 digits) easy to be read with a telescope from up to $100 \mathrm{~m}$. Almost 4,000 chicks have been unequivocally sexed by DNA. Furthermore, from 1998 onwards $\sim 10000$ chicks have been visually sexed according to tarsus shape (Figuerola et al. 2006) with an error probability (range $0.01-0.2$ ) dependent on year and ringer (see Santoro et al. 2013 for details). Until 2002, the Natural Processes Monitoring Team of the EBD-CSIC made an accurate estimate of both population size and productivity by conducting exhaustive counts of nests and fledglings during banding operations, combined with counts from vantage points (details in Mañez and Rendón-Martos 2009). Afterwards, density at the colony increased to such an extent that precise counting of fledglings became difficult and estimates refer to the minimum number of fledglings produced, thus resulting in low-biased productivity estimates. For the second period (2003-2007), productivity estimates remained roughly constant showing no decrease (details in Mañez and Rendón-Martos 2009).

\section{Analytical approach}

Our approach combines capture-recapture (CR) estimates of local demographic parameters, counts, matrix population modeling (Caswell 2001), and observations of Doñana-born individuals outside their natal site. First, we used CR modeling to test hypotheses on intrinsic and extrinsic factors regulating local survival and recruitment of new breeders into the colony. The CR data we used were exclusively those obtained by marking of chicks and their subsequent resightings as adults at the FAO colony. Thus, we could not distinguish mortality from permanent emigration away from the natal colony and the estimated probability of recruitment was specific for FAO-hatched individuals recruiting into the same colony (local recruitment). Second, we used $\mathrm{CR}$ and count estimates within matrix models to assess the contribution of local recruitment vs. immigration and therefore the source-sink role of the study population. Third, we performed a sensitivity analysis to determine the importance of each 
intrinsic parameter (survival, recruitment, and productivity) on population growth. Last, we described the range expansion through the study period from observations of marked individuals born in Doñana.

\section{Survival and recruitment analysis}

We performed a multievent CR analysis (Pradel 2005) to test hypotheses on the local survival and local recruitment (see above) by using resightings of individuals $(n=5565)$ at the FAO colony during the breeding season (April-July) between 1996 and 2007. Observations at the breeding colony after 2007 were sparse and therefore excluded from analyses. We assumed that all the individuals seen at the colony were breeders so that local recruitment estimates corresponded to the annual probabilities of becoming a new breeder into the colony. These estimates would be high-biased if nonbreeders visited the colony regularly. Our observations suggest this is not the case, however, as reproductive behavior was observed in many first-year and adult birds, and there is no evidence of helpers at the nest in this species (Davis and Kricher 2000). The multievent approach (Pradel 2005) aimed to deal with uncertainty in the sex determination of ibis chicks by accounting for sex identification by both DNA- and visual sexing.

In this study, we considered five biological states: $†$ for permanently emigrated away from the FAO colony or dead, $\rightarrow \mathrm{NB}$ for female nonbreeder, alive, $\rightarrow \mathrm{B}$ for female breeder, alive, ${ }^{\top} \mathrm{NB}$ for male nonbreeder, alive, and ${ }^{7} \mathrm{~B}$ for male breeder, alive (see Appendix S1 for details of the modeling approach). We assumed that once an individual became a breeder it remained so until death, and we considered two age classes, both for local survival and recruitment rate (Fig. 1). These states were mediated by four events, numbered as they appear in the encounter histories: (0) not seen, (1) seen and visually sexed as a female, (2) seen and visually sexed as a male, and (3) seen but sex not determined. Five parameters were estimated: (1) Initial State, the probability an individual was a female chick when ringed at time $t$; (2) Survival, $P$ of surviving and not emigrating permanently between $t$ and $t+1$; (3) Recruitment, conditional on Survival, $P$ of recruitment between $t$ and $t+1$; (4) Resighting, $P$ of being resighted at time $t+1$; (5) Visual Sexing, conditional on Resighting, $P$ of being visually sexed when first captured and marked; and (6) Correctness, conditional on Visual Sexing, $P$ that visual sex was correct. Models were run in E-SURGE (version 1.8.5) (Rouan et al. 2009).

We used U-CARE (version 2.3.2) (Choquet et al. 2005) to perform a goodness-of-fit test of the general CormackJolly-Seber model on all observations of marked individuals (except first capture) and found no significant lack of fit (Global Test: $\chi^{2}=21.6, \mathrm{df}=24, P=0.6$ ). Parameters were modeled separately in sequential steps to limit both the influence of the modeling order and limit the number of models (details in Appendix S2; see also Grosbois and Tavecchia 2003). According to previous analyses (Santoro et al. 2013) both Visual Sexing and Correctness were fixed as depending on the cohort. As a general rule, throughout the model simplification process we retained the structure of models in which $\mathrm{AIC}_{\mathrm{c}}$ (Akaike Information Criterion corrected for small sample sizes) was at least two units lower than others.

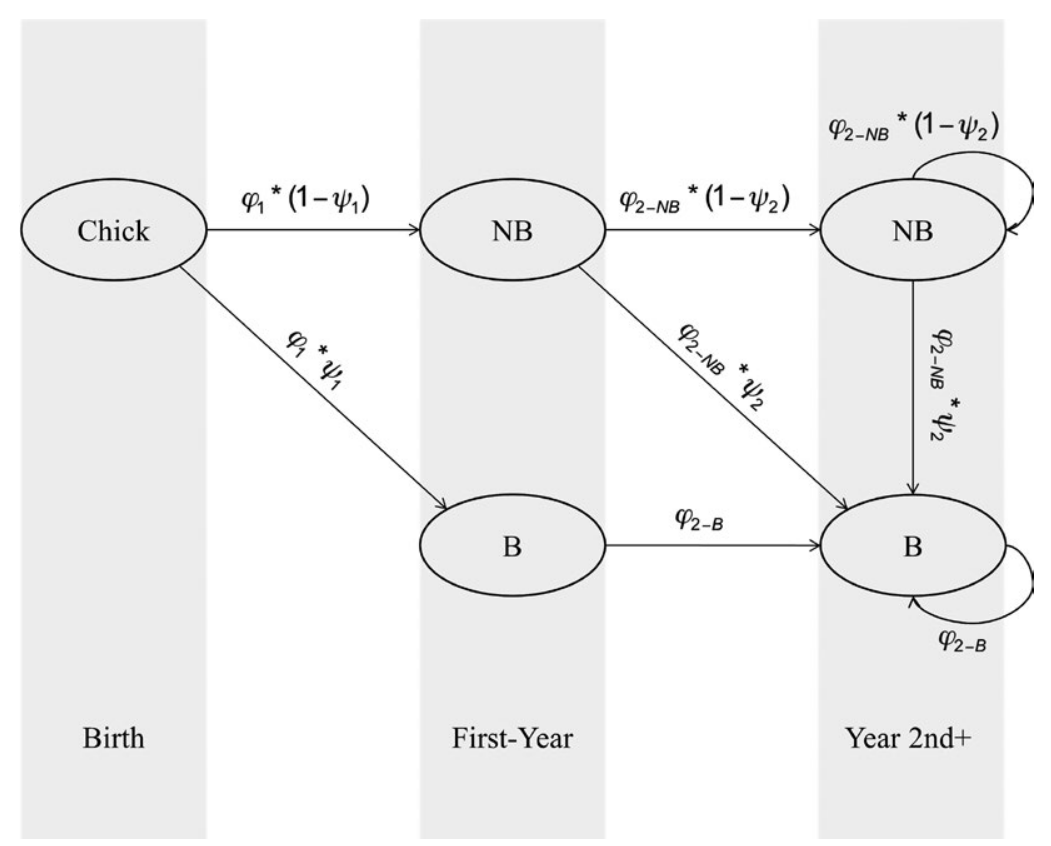

FIG. 1. Life-history diagram of Glossy ibis at the FAO colony. Notation: NB, nonbreeder; $B$, breeder; $\phi$, local survival probability; $\psi$, local recruitment probability; subscripts 1 and 2 refer respectively to specific probabilities for the first year of life and for later years. Transitions toward dead or permanently emigrated states are not explicitly represented. 
TABLE 1. Capture-recapture testing of hypotheses about temporal variation in local recruitment.

\begin{tabular}{|c|c|c|c|c|c|c|c|c|c|}
\hline $\begin{array}{l}\text { Model } \\
\text { no. }\end{array}$ & Model effects & $\mathrm{np}$ & Dev & $\mathrm{AIC}_{\mathrm{c}}$ & $\Delta \mathrm{AIC}_{\mathrm{c}}$ & $w_{i}$ & $F_{1,7}$ & $P$ & $R^{2}$ \\
\hline R1 & Cohort (1996-2002 vs. others) & 37 & 17700.58 & 17774.96 & 0.00 & 0.48 & 6.39 & 0.04 & 0.92 \\
\hline $\mathrm{R} 2$ & Time (1996-2002 vs. others) & 37 & 17702.18 & 17776.56 & 1.60 & 0.21 & 6.27 & 0.04 & 0.90 \\
\hline R3 & Time & 42 & 17692.29 & 17776.79 & 1.83 & 0.19 & & & \\
\hline R4 & Cohorts & 42 & 17693.22 & 17777.72 & 2.76 & 0.12 & & & \\
\hline R5 & Flood- $i$ & 35 & 17743.67 & 17814.02 & 39.05 & 0.00 & 3.21 & 0.12 & 0.46 \\
\hline R6 & Flood- $i+1$ & 35 & 17747.05 & 17817.40 & 42.43 & 0.00 & 2.96 & 0.13 & 0.43 \\
\hline R7 & Time (1996-2002 vs. 2003-2006) & 35 & 17763.96 & 17834.30 & 59.34 & 0.00 & 1.72 & 0.23 & 0.25 \\
\hline $\mathrm{R} 8$ & Cohort (1996-2002 vs. 2003-2006) & 35 & 17765.02 & 17835.37 & 60.40 & 0.00 & 1.64 & 0.24 & 0.24 \\
\hline R9 & Population size & 35 & 17766.54 & 17836.88 & 61.92 & 0.00 & 1.53 & 0.26 & 0.22 \\
\hline $\mathrm{R} 10$ & Dry years & 35 & 17783.53 & 17853.87 & 78.91 & 0.00 & 0.28 & 0.61 & 0.04 \\
\hline $\mathrm{R} 11$ & Constant & 34 & 17787.28 & 17855.61 & 80.65 & 0.00 & & & \\
\hline $\mathrm{R} 12$ & Fecundity & 35 & 17787.14 & 17857.49 & 82.53 & 0.00 & 0.01 & 0.92 & 0.00 \\
\hline
\end{tabular}

Notes: These models were parameterized according to the structure selected in the previous step of model selection (see Methods and Table $\mathrm{C} 1$ for details). Thus, Recruitment depended on the additive effects of age, sex and each of the covariates reported here Model notation: $\mathrm{np}$, number of estimable parameters; Dev, relative deviance; AIC, Akaike information criterion corrected for small sample size; $\triangle \mathrm{AIC}$, the difference in $\mathrm{AIC}_{\mathrm{c}}$ between the current model and the lowest $\mathrm{AIC}_{\mathrm{c}}$ value; $w_{i}$, Akaike's weight, $F_{1,7}, F$-statistic; $R^{2}$, percentage of deviance explained by the current model.

Where other models existed within $2 \mathrm{AIC}_{\mathrm{c}}$ units, the least parameterized was retained (Burnham and Anderson 2002). Due to data sparseness, we set Survival as constant over time and tested only for the effects of age (first-year individuals vs. adults), sex, and breeding status. For Recruitment, besides variation due to age and sex, we also evaluated the following time-varying effects: (1) breeding success at time $t,(2)$ flooded marsh surface at time $t$ and $t+1$, (3) population size at the FAO colony, (4) dry vs. wet years, and (5-6) time and cohort effects before and after the establishment of other breeding colonies in Doñana (see Santoro et al. 2013 for details of parameters [2] and [4]). We used the analysis of deviance (ANODEV) procedure to test the effect of each timevarying covariate by comparing the deviance of the null, full time-dependent and covariate models; furthermore, we estimated the size of each covariate effect by the amount of deviance explained (Skalski et al. 1993).

The default Wald method is inappropriate to calculate confidence intervals $(95 \%)$ of boundary estimates (close to 0 or 1) (Gimenez et al. 2005). Therefore, we used the profile likelihood method by iteratively fixing the parameter to decreasing (if close to 1) or increasing (if close to 0) values until the model deviance changed significantly (which corresponds to a change of 3.84 in deviance, see Tavecchia et al. 2009).

\section{Contributions of local recruitment and immigration to population growth}

According to the $\mathrm{CR}$ analyses, local recruitment varied mainly between a first period when the entire Doñana population was breeding at FAO and a second one when satellite colonies were created. Hence, in this section we considered two periods: 1996-2003 (only FAO) and 2003-2007 (FAO plus others).
First, for each period we calculated the observed average breeding population growth rate and its 95\% CI by performing a regression of $\log \left(N_{i+1} / N_{i}\right)$ against year ${ }_{i+1} /$ year ${ }_{i}$ where $N_{i}$ are the number of pairs counted in year $i$ (details in Appendix S3 and supplement; see also Morris and Doak 2002). Second, for each period we calculated the predicted growth rate as the dominant eigenvalue ( $\mathrm{R}$ package popbio; Stubben and Milligan 2007) of the Leslie projection matrix built with estimates of local survival, local recruitment, and productivity (Fujiwara and Caswell 2002, see next section). Since after 2002 only minimum productivity estimates were available and no differences between the mean productivity calculated for the two periods existed, we used a single estimate (mean and SD) calculated from data collected until 2002. According to CR model selection, we considered two age classes (first-year vs. others) for both survival and recruitment rates and, for the second age class, a different survival rate for nonbreeding and breeding individuals. Capture-recapture estimates were obtained from a model (R7 in Table 1) including the same variables as the best model ( R1 in Table 1) except for the inclusion of a twoperiod (1996-2003 and 2003-2007) time-effect on local recruitment. Although this was done at the cost of losing some realism, it allowed us to maintain a simple and logical framework to test the population dynamics over these two periods, which were strikingly different, as indicated by CR model selection. We calculated the population growth rate by applying a standard female-based time-invariant matrix model (Caswell 2001) that considered the following stages: new-born individuals, nonbreeder first-year individuals, nonbreeder adults $(>1 \mathrm{yr}$ old), breeding first-year individuals, and breeding adults. As for CR analyses, we assumed that once an individual became a breeder, it remained so until death. Thus, the Leslie matrix was defined as: 


$$
A=\left[\begin{array}{c}
\varphi_{1} \times \psi_{1} \times f \times 0.5 \\
\varphi_{1} \times\left(1-\psi_{1}\right) \\
0 \\
\varphi_{1} \times \psi_{1} \\
0
\end{array}\right.
$$

$$
\begin{gathered}
\varphi_{2-\mathrm{NB}} \times \psi_{2} \times f \times 0.5 \\
0 \\
\varphi_{2-\mathrm{NB}} \times\left(1-\psi_{2}\right) \\
0 \\
\varphi_{2-\mathrm{NB}} \times \psi_{2}
\end{gathered}
$$

$\varphi_{2-B} \times f \times 0.5$
0
0
0
$\varphi_{2-B}$

where $\phi$ represents the local survival rate, $\psi$ the recruitment rate, $f$ the fecundity (productivity) and the subscripts " 1 ", " 2 ", "NB", and " $B$ " represent respectively the first vs. later years of life, nonbreeder and breeder (Fig. 1).

While the predicted growth rate depends exclusively on locally born individuals, the observed rate depends also on immigration (see Appendix S3 and supplement). After Peery et al. (2006), we investigated the source-sink nature of the study population by testing whether count-derived and matrix-predicted growth rates were different from 1 (stable population) and if the observed growth rate was significantly higher than the matrix-predicted rate (criteria summarized in Table S3). When that was the case, we included in the Leslie projection matrix another state, immigrants (see Doxa et al. 2013), and iteratively repeated ( $n=10$ 000; see next section) the process to calculate the annual average number of female immigrants needed to match the observed population size.

\section{Simulations and sensitivity}

For two periods (1996-2003, 2003-2007) we used Latin Hypercube Sampling (R package lhs, Carnell 2012) to create 10,000 simulations, each consisting of a random parameter set from within realistic ranges $(95 \%$ CI estimates) of the demographic parameters used in the Leslie matrix. Apart from estimating the predicted growth rate and number of immigrants, these simulations were used to perform a sensitivity analysis ( $\mathrm{R}$ package sensitivity, Pujol et al. 2014) to determine the importance of each demographic parameter (productivity, age-specific local survival and recruitment) on the predicted growth rate. Details of the matrix modeling and simulations (R-code) are given in Appendix S3 and supplement.

\section{Breeding dispersal of Doñana-born individuals}

We described the spatial distribution of resightings of Doñana-born individuals over the last 19 breeding seasons. We only considered resightings more than $100 \mathrm{~km}$ away from Doñana, and classified them separately according to whether or not the individual was recorded as a breeder. In order to focus on breeding dispersal, we only considered resightings during the core breeding period (May-July), except for individuals explicitly reported as breeders.

\section{RESULTS}

\section{Local survival and recruitment}

Based on the estimates of the best model ( $\mathrm{R} 1$ in Table 1), local survival (i.e., the probability of surviving and not emigrating from the area) was similar for first-year males and females $(0.75,95 \% \mathrm{CI}=0.65-0.83)$. Adult male breeders had a much higher local survival probability $(0.85,95 \% \mathrm{CI}=0.81-0.89)$ than nonbreeders $(0.01,95 \%$ CI $=0-0.68)$. The reverse occurred among adult females, with higher estimates for nonbreeders $(0.99,95 \% \mathrm{CI}=0.78-1)$ than for breeders $(0.73,95 \%$ $\mathrm{CI}=0.68-0.78$ ) (see Appendix S2, Table S1 for model selection on Survival).

None of the local recruitment hypotheses (reproductive success RSH, conspecific attraction $\mathrm{CAH}$ and food availability hypotheses FAH) was supported. Local recruitment was not directly related to breeding success (contrary to RSH), population size (contrary to $\mathrm{CAH}$ ), flooded marsh surface (contrary to FAH), or wet/dry years. Local recruitment differed between cohorts hatched before and after the creation of satellite colonies in 2004 (model R1 in Table 1), however, when the population size was about 700 breeding pairs. Indeed, the model accounting for this effect was strongly supported, explaining about $92 \%\left(F_{1,7}=6.39, P<0.05\right)$ of local recruitment variation over time. According to the model, local recruitment was higher and constant for cohorts born before 2003, but progressively declined for subsequent cohorts (Fig. 2). A model accounting for an

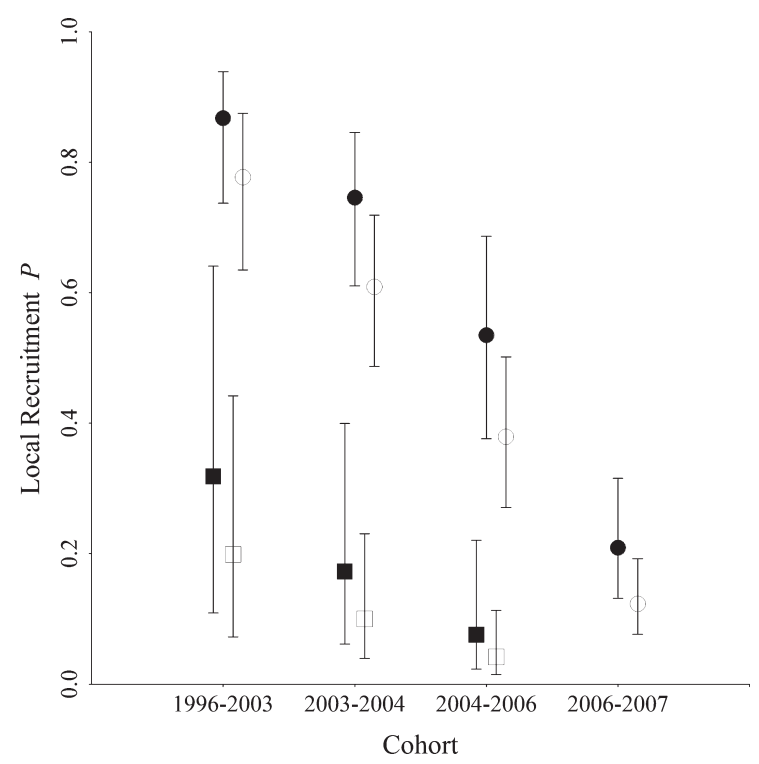

FIG. 2. Local Recruitment. Local recruitment probabilities $\left( \pm 95 \% \mathrm{CI}\right.$ ) according to the lowest $\mathrm{AIC}_{\mathrm{c}}$ model, accounting for the effect of age, sex, and cohort. According to this model, the local recruitment probability over the first period (1996-2003) is constant. Notation: filled circles refer to first-year males, filled squares to first-year females, empty circles to adult males, empty squares to adult females. 
analogous time (instead of cohort) effect on recruitment rate was similarly supported by the data (model $\mathrm{R} 2$ in Table $\left.1, \Delta \mathrm{AIC}_{\mathrm{c}}=1.60\right)$. On average, the local recruitment probability was much higher for first-year individuals than for adults, and slightly higher for males than females (Fig. 2, see Appendix S2, Table S1 for model selection of time-unvarying effects on Recruitment). Overall, the highest probabilities of local recruitment were estimated for first-year individuals during the first period (1996-2003) (males: 0.87, 95\% CI: 0.74-0.94; females: 0.78, 95\% CI: 0.64-0.87).

Resighting probabilities varied with time (Appendix S1, Fig. S1) and Initial State probability was constant across the study period $(0.53,95 \%$ CI $0.49-0.57)$ (see Appendix S2, Table S1 for details).

\section{Population growth}

The annual average growth rate of the FAO population was significantly greater than one $\left(\lambda_{\text {obs- } 1}=1.92\right.$, 95\% CI 1.45-2.38, $\left.Z=3.85, P_{\text {two-tailed }}<0.001\right)$ through the first period (1996-2003) when recruitment at Doñana was possible only at the FAO colony, but was lower and not significantly different from one from then onwards $\left(\lambda_{\text {obs- } 2}=1.22,95 \%\right.$ CI $\left.0.80-1.87, Z=1.04, P_{\text {two-tailed }}=0.30\right)$ (Fig. 3).

The annual average number of fledglings per pair as estimated by counts until 2002 was 2.12 (95\% CI 1.38-2.86).

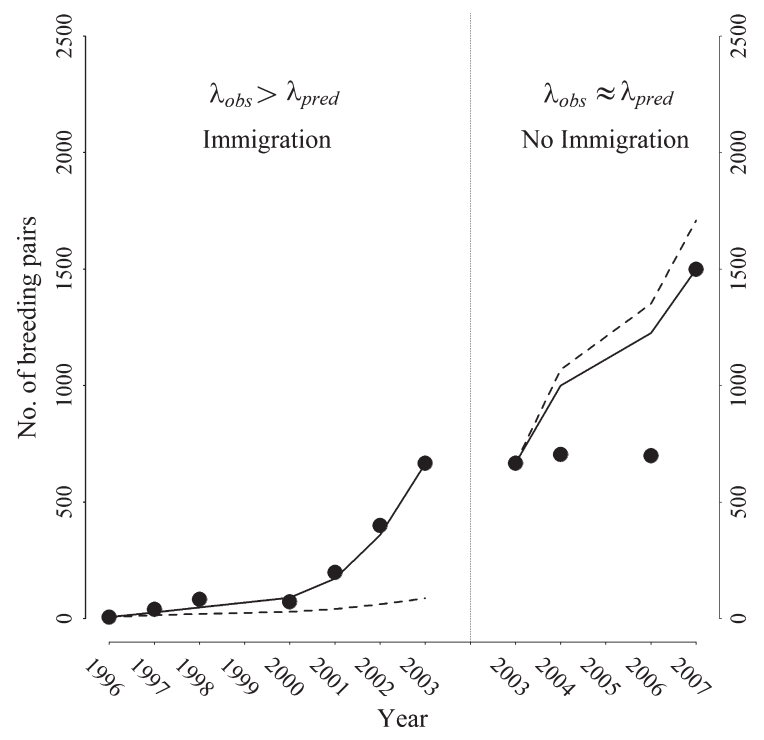

FIG. 3. Population growth rate. The population trend observed and predicted by projection matrix modeling (without immigration) over the first period (1996-2003) when only one breeding site (FAO) existed in Doñana, and over the second period (2003-2007) when other colonies appeared. Notation: filled circles, count estimates; filled line, the trend line fitting the count estimates; dashed line, matrix-model predicted growth line. $\lambda_{\text {obs }}$ and $\lambda_{\text {pred }}$ refer to the annual average finite growth rate $\left(N_{t+1} / N\right)$ calculated by count estimates and matrix modeling respectively.
According to the matrix model (i.e., without immigration influx), the predicted annual growth rate would have been significantly positive for the first period $\left(\lambda_{\text {pred-1 }}=1.43\right.$, 95\% CI 1.21-1.66, $\left.Z=3.79, P_{\text {two-tailed }}<0.001\right)$, and nonsignificantly positive during the second period $\left(\lambda_{\text {pred-2 }}=1.26,95 \%\right.$ CI 1.10-1.43, $\left.Z=1.43, P_{\text {two-tailed }}=0.15\right)$ (Fig. 3).

Over the first study period (1996-2003), the observed annual growth rate exceeded that predicted by the matrix model $\left(Z=5.36, P_{\text {one-tailed }}<0.001\right)$, indicating a net immigrant influx estimated at 58 female immigrants per year (95\% CI 35-92). Over the second period (2003-2007), the observed growth rate was not significantly different from the matrix-predicted rate $\left(Z=-0.38, P_{\text {two-tailed }}=0.71\right)$, indicating that no net immigration occurred.

According to the criteria (Appendix S3, Table S1) for defining the source-sink role a local population may play within a metapopulation, the FAO population would be categorized as "stable, open and a potential source" during the first period (1996-2003) and "increasing, closed or a source" throughout the second period (2003-2007).

\section{Sensitivity analysis}

The number of fledglings per pair had the greatest potential impact on the predicted population growth rate (Appendix S3, Fig. S1). We found that, without any contribution from immigration and keeping the other demographic parameters constant, 3.85 fledglings per pair ( $\sim 1.8$ times the observed value) would have been needed to achieve the observed growth rate through the first period.

\section{Breeding dispersal distribution area}

Three hundred and forty-nine Doñana marked individuals were resighted elsewhere during the breeding season: 61 were reported as active breeders. The first record occurred in 1999 coinciding with the first dry year in Doñana, but the next resighting was not until the next local drought (in 2005) when ibis did not breed in Doñana (Appendix S1, Table S1). The observations came from an area stretching from Southwest Morocco to Scotland to the western shore of the Black Sea (Fig. 4). An individual hatched in Doñana was seen in July 2008 in Trinidad and Tobago and another in September 2010 in Barbados.

\section{Discussion}

Our study shows that a new waterbird colony can experience a sharp increase largely due to immigration, at least until density-dependent mechanisms arise. As well as immigration, high productivity and early recruitment may facilitate the creation of a new source population driving the expansion of the species. Our findings suggest that males and females may follow different dispersal strategies depending on interactions between environmental and demographic factors. 


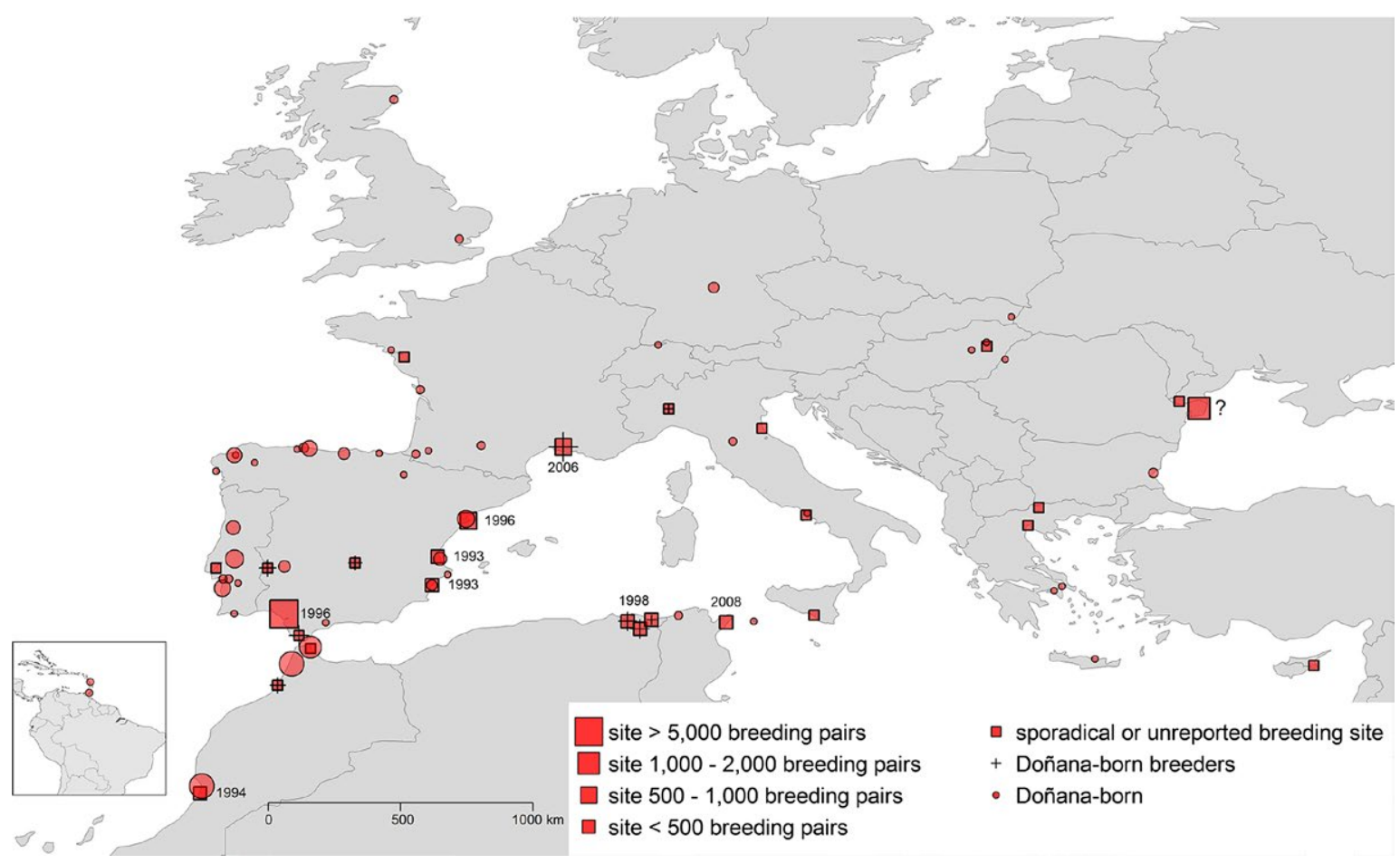

FIG. 4. Map of resightings. Observations of Doñana-born individuals more than $100 \mathrm{~km}$ away from their natal colony during the breeding season (May-July). A distinction is made between individuals for which breeding activity was reported by the resighter (cross symbol) and individuals for which no information on breeding activity was reported (full circle symbol). Observations of two individuals in the Caribbean are shown in the left side of the map. The location of a number of known breeding areas is reported (square symbol) and the year of formation of the colony is indicated when known; the size of the breeding location symbol is proportional to the most recent estimated number of breeding pairs (from 2010 onward). The smallest square symbol refers to occasional breeding sites the authors are aware of but which have not previously been reported in the literature.

\section{Local recruitment}

Previous studies in North American populations provided conflicting results about age at first reproduction for glossy ibis, suggesting that sexual maturity was reached at $3 \mathrm{yr}$ of age in the core of their distribution area (Byrd 1978) and at $1 \mathrm{yr}$ for populations at the edge of their range (Miller and Burger 1978). We found that, for most individuals, first breeding occurred at the age of one. Age at first reproduction is the first demographic parameter to change as population density increases (Stearns 1992), and this may explain inter-population differences in this parameter.

We found no support for the "conspecific attraction hypothesis" (Stamps 1988) or the "reproductive success hypothesis" (Danchin et al. 1998), because neither breeding success nor colony size was related to local ibis recruitment. This might be because using public information (sensu Valone 1989) may be favoured only when the environment is predictable from one season to the next (Boulinier and Danchin 1997). Doñana provides good but highly variable conditions for many colonial waterbirds (Ramo et al. 2013).

Even though we did not find a linear relationship between local recruitment and population size, density-dependence was likely, as indicated by the cohort effect on local recruitment before and after the creation of satellite colonies to which individuals hatched at FAO may recruit with negligible dispersal costs. We found no evidence for the "food availability hypothesis" (Porter and Coulson 1987) or for the effect of dry years on local recruitment. Flooded area may not have been a reliable proxy for availability of resources, since extensive flooding may reduce resource accessibility owing to the increase in water depth (see Santoro et al. 2013). It is possible that we overlooked a negative effect of dry years on local recruitment rate because of the concurrent decrease in local recruitment that started after the formation of satellite colonies in 2004 (just before the second dry year). A previous CR analysis of post-breeding data indicated that dry years at Doñana strongly enhanced permanent emigration (Santoro et al. 2013), and the present study confirms this pattern. The first observation of a Doñana-hatched individual dispersing elsewhere coincided with the first dry year (1999), and there were no further observations until the next one (2005).

A basic assumption we made for our modeling approach was that once individuals were first recruited, they remained as breeders. In long-lived species, however, young individuals may visit a reproductive colony without 
breeding, or skip breeding for some years (Sanz-Aguilar et al. 2011). Estimates from our modeling approach would be biased if violation of this assumption resulted from either permanent emigration of individuals after their first breeding or by Markovian temporary emigration depending on breeding status on the previous occasion (Schaub et al. 2004). Neither permanent nor Markovian temporary emigration were detected by the "2.CT" component of the goodness of fit test (signed statistic for trap-dependence $=0.08, P=0.94)$, however, which has good statistical power (Choquet et al. 2005).

\section{Local survival}

Adult local survival estimates differed greatly among sexes and reproductive states, probably due more to variation in dispersal than in survival. Our findings suggest that males unable to breed in their first year of life were much more prone to disperse than females. Previous studies in this population (Santoro et al. 2013, 2015) suggested that: (1) as colony size increased, more female than male chicks died during the parental care period, gradually biasing the fledging sex ratio towards males; and (2) the opposite temporal pattern appeared among the post-fledging sex ratio, suggesting that sex-related dispersal overrides the excess of one sex among fledglings. Thus, it seems likely that first-year males outnumbered first-year females, suffering higher competition for mating and were therefore more likely to disperse if they failed at their first breeding attempt as juveniles. This is also consistent with previous evidence (Santoro et al. 2013 , 2015) that relatively more males dispersed as the population size increased. Alternative, nonexclusive explanations exist, however. Sexual differences in costbenefit ratios for dispersal might also be explained by other differences between sexes, such as territoriality, size dimorphism, or by greater proportions of male immigrants (see Clobert et al. 2012).

\section{Population growth}

Often, new colonies are more productive and fastergrowing than old colonies (Porter and Coulson 1987, Tims et al. 2004, Kildaw et al. 2005, but see Coulson and Coulson 2008), especially when they are promoting the range expansion of the species (Phillips 2009). Likely explanations are: (1) new colonies are fueled by dispersing, inexperienced individuals and inhabit unexploited, good-quality patches with little competition for food (Porter and Coulson 1987, Oro and Ruxton 2001, Tims et al. 2004); or (2) new and highly productive colonies attract local and nonlocal recruiters (Danchin et al. 1998) dispersing from old, saturated colonies with high levels of competition. Our study suggests that breeding success and recruitment may form a positive feedback loop increasing the population growth rate. First, we found high productivity over the entire study period (more than two fledglings per pair) compared with other studies on this species ( 0.4-1 fledglings/pair in North America and Australia; Williams 1975, Burger 1978, Miller and Burger 1978, Lowe 1983). High fecundity rates were also found in a recently settled glossy ibis population in Algeria (Boucheker et al. 2009). Second, both local and nonlocal recruitment contributed to the population increase, which was steep until 2003. The effect the immigration had on population increase during the initial phase appears substantial (58 females/yr), and almost double the recorded mean breeding success would have been necessary to achieve the observed population growth rate in its absence. Furthermore, the observed early age at recruitment might have been related to the high productivity of the colony, as found with cormorants(Frederiksen and Bregnballe 2001).

The growth rate of long-lived bird populations is mostly affected by adult survival, whereas that of shortlived species usually depends more on fecundity (Sæther and Bakke 2000). The population growth rate was mostly affected by productivity (Appendix S3: Fig. S1), however, which suggested that although it is a long-lived species (up to 20 yrs of age, Davis and Kricher 2000), glossy ibis may achieve very high reproductive outputs.

\section{Source-sink dynamics}

Several studies support the idea that populations at the edge of their distribution range tend to facilitate dispersal and range expansion through behavioral (e.g., aggressiveness; Duckworth and Badyaev 2007) or life-history (e.g., fecundity, dispersal propensity; Phillips 2009, Lindström et al. 2013) characteristics. In Doñana, before the formation of satellite glossy ibis colonies, natal recruiters faced two very different strategies: recruiting locally or breeding somewhere far away. However, since 2004 they faced a third option: recruiting at a neighboring colony inside Doñana, from which resighting data were not collected due to logistical constraints (Mañez and Rendón-Martos 2009). While until 2003 the entire Doñana population bred at the FAO, since 2004 the local recruitment, immigration rate and growth rates reported herein, refer uniquely to the FAO colony which overall was still growing after 2004 (Santoro et al. 2010). Thus, although the FAO/Doñana population was a potential source throughout the first period (Appendix S3: Table S1; Peery et al. 2006), it is highly likely that it acted as a source population after 2004 and continued to do so, as suggested by the many Doñana-born individuals breeding elsewhere in recent years (Fig. 4).

\section{Final remarks}

The glossy ibis is catalogued as of conservation concern and in decline in Europe (Burfield and van Bommell 2004). The origin of the Doñana colonizers and immigrants is uncertain; but long-distance recoveries of marked individuals suggest they may have come from populations breeding in East Europe (Black Sea) that 
winter in Western Africa (Figuerola et al. 2004). Resightings of Doñana-born individuals make clear that the metapopulation range includes the Mediterranean basin, Western Europe and Eastern Europe. As demonstrated by many breeding sites occupied only sporadically (Fig. 4), the glossy ibis is a plastic species adapted to highly variable and unpredictable habitats with great capacity to disperse when breeding conditions are adverse. The Doñana population has enabled this species to rapidly expand to a number of suitable areas in Western Europe and the Mediterranean basin.

In conclusion, our study illustrates how the high rate of increase of a newly established population can be boosted by high immigration more than by intrinsic demographic parameters. At the same time, under favorable conditions, this process can be so fast that such a new population can itself rapidly become a source population driving range expansion.

\section{ACKNOWLEDGMENTS}

This study was funded by projects from the Ministerio de Economia y Competitividad ("Ecología del morito en Doñana: implicaciones para la conservación y gestión del Parque Nacional y su entorno") and Junta de Andalucía ("Las aves acuáticas de Doñana y el cultivo del arroz: la interacción entre la agricultura y la conservación de las zonas humedas"). Ringing of chicks and monitoring of breeding populations was possible thanks to El Equipo de Seguimiento de Procesos Naturales (EBD-CSIC). The molecular sexing was performed by Molecular Ecology Lab (LEM). We are especially grateful to L. Garcia, J.L. Arroyo, J.L. del Valle, M. Mañez, F. Ibañez, A. Chico, R. Rodriguez, J.L. Barroso, M. Bauza, M. Pérez, M. Lobon, O. Gonzalez, J.C. González, C. Pérez, C. Moreno, E. García, R. Soriguer, A. Pastoriza, M. Vazquez, D. Aragones, and many volunteers that helped with the ringing of glossy ibis chicks.

\section{Literature Cited}

Amezian, M., R. El Khamlichi, and A. Elbanak. 2012. Breeding of Glossy Ibis Plegadis falcinellus in the mixed heronry adjacent to Smir marshes, northern Morocco. Alauda 80:33-38.

Boucheker, A., R. Nedjah, F. Samraoui, R. Menaï, and B. Samraoui. 2009. Aspects of the breeding ecology and conservation of the Glossy Ibis in Algeria. Waterbirds 32:345-351.

Boulinier, T., and E. Danchin. 1997. The use of conspecific reproductive success for breeding patch selection in terrestrial migratory species. Evolutionary Ecology 11:505-517.

Brichetti, P. 1986. Nidificazione di nitticora nycticorax nutycorax e mignattaio Plegadis falcinellus in Puglia. Avocetta 10:59-60.

Burfield, I. and F. van Bommell. 2004. Birds in Europe: population estimates, trends, and conservation status. BirdLife International, Cambridge, UK.

Burger, J. 1978. Competition between cattle egrets and native North American herons, egrets, and ibises. Condor 80:15-23.

Burnham, K. P., and D. R. Anderson. 2002. Model selection and multimodel inference: a practical information-theoretic approach. Second edition. Springer-Verlag, New York, New York, USA.

Byrd, M. 1978. Dispersal and movements of six North American ciconiiforms. Pages 161-185 in A. Sprunt IV, J. C. Ogden, and S. Winckler, editors. Wading birds. National Audubon Society, Research Report, New York, New York, USA.

Carnell, R. 2012. lhs: Latin hypercube samples.

Caswell, H. 2001. Matrix Population Models, 2nd edn. Sinauer Ass, Sunderland, MA.

Choquet, R., A.-M. Reboulet, J.-D. Lebreton, O. Gimenez and R. Pradel. 2005. U-CARE 2.2 user's manual. CEFE, Montpellier, France.

Clobert, J., M. Baguette, T. G. Benton and J. M. Bullock. 2012. Dispersal ecology and evolution. Oxford University Press, Oxford, United Kingdom.

Coulson, J., and B. Coulson. 2008. Measuring immigration and philopatry in seabirds; recruitment to Black-legged Kittiwake colonies. Ibis 150:288-299.

Danchin, E., T. Boulinier, and M. Massot. 1998. Conspecific reproductive success and breeding habitat selection: implications for the study of coloniality. Ecology 79:2415-2428.

Davis Jr, W. E. and J. Kricher. 2000. Glossy Ibis (Plegadis falcinellus). The Birds of North America:20.

Doxa, A., A. Besnard, A. Bechet, C. Pin, J.-D. Lebreton, and N. Sadoul. 2013. Inferring dispersal dynamics from local population demographic modeling: the case of the slenderbilled gull in France. Animal Conservation 16:684-693.

Duckworth, R. A., and A. V. Badyaev. 2007. Coupling of dispersal and aggression facilitates the rapid range expansion of a passerine bird. Proceedings of the National Academy of Sciences of the United States of America 104:15017-15022.

Figuerola, J., M. Mañez, F. Ibáñez, L. García and H. Garrido. 2004. Morito común Plegadis falcinellus. Pages 74-76. Libro rojo de las Aves de España. Dirección general para la Biodiversidad. SEO/BirdLife, Madrid, Spain.

Figuerola, J., L. García, A. J. Green, F. Ibáñez, M. Mañez, J. L. Del Valle, H. Garrido, J. L. Arroyo, and R. Rodríguez. 2006. Sex determination in glossy ibis chicks based on morphological characters. Ardeola 53:229-235.

Forslund, P., and T. Pärt. 1995. Age and reproduction in birds - hypotheses and tests. Trends in Ecology \& Evolution 10:374-378.

Frederiksen, M., and T. Bregnballe. 2001. Conspecific reproductive success affects age of recruitment in a great cormorant, Phalacrocorax carbo sinensis, colony. Proceedings of the Royal Society B: Biological Sciences 268:1519-1526.

Fujiwara, M., and H. Caswell. 2002. Estimating population projection matrices from multi-stage mark-recapture data. Ecology 83:3257-3265.

Gaston, K. 2009. Geographic range limits: achieving synthesis. Proceedings of the Royal Society B: Biological Sciences 276:1395-1406.

Gimenez, O., R. Choquet, L. Lamor, P. Scofield, D. J. Fletcher, J. D. Lebreton, and R. Pradel. 2005. Efficient profilelikelihood confidence intervals for capture-recapture models. Journal of Agricultural, Biological, and Environmental Statistics 10:184-196.

Grosbois, V., and G. Tavecchia. 2003. Modeling dispersal with capture-recapture data: disentangling decisions of leaving and settlement. Ecology 84:1225-1236.

Grussu, M. 2004. Nuovo sito di nidificazione di Mignattaio, Plegadis falcinellus, in Sardegna. Rivista Italiana di Ornitologia 73:171-173.

Hanski, I. 1998. Metapopulation dynamics. Nature 396:41-49.

Kayser, Y., T. Blanchon, M. Gauthier-Clerc, and J. Petit. 2009. L'Ibis falcinelle Plegadis falcinellus nicheur régulier en Camargue. Ornithos 16:404-406.

Kildaw, S., D. Irons, D. Nysewander, and C. Buck. 2005. Formation and growth of new seabird colonies: the significance of habitat quality. Marine Ornithology 58:49-58. 
Le Galliard, J. F., M. Massot and J. Clobert. 2012. Dispersal and range dynamics in changing climates: a review. Pages 318-336 in J. Clobert, M. Baguette, T. G. Benton, and J. M. Bullock, editors. Dispersal ecology and evolution. Oxford University Press, Oxford.

Lindström, T., G. Brown, S. Sisson, B. Phillips, and R. Shine. 2013. Rapid shifts in dispersal behavior on an expanding range edge. Proceedings of the National Academy of Sciences of the United States of America 110:13452-13456.

Lowe, K. W. 1983. Egg size, clutch size and breeding success of the Glossy Ibis Plegadis falcinellus. Emu 83:31-34.

Mañez, M. and M. Rendón-Martos. 2009. El morito común, la espátula común y el flamenco común en España. Pages 1-122 in M. Máñez, and M. Rendón-Martos, editors. Población en 2007 y método de censo. SEO/Birdlife, Madrid, Spain.

Marion, L., and P. Marion. 2011. Première reproduction prouvée de l'Ibis falcinelle Plegadis falcinellus au lac de GrandLieu (Loire-Atlantique). Alauda 79:215-219.

Miller, L., and J. Burger. 1978. Factors affecting nesting success of the glossy ibis. Auk 95:353-361.

Møller, A. 2006. Sociality, age at first reproduction and senescence: comparative analyses of birds. Journal of Evolutionary Biology 19:682-689.

Morris, K. W. and D. F. Doak. 2002. Quantitative conservation biology: the theory and practice of population viability analysis. Sinauer, Sunderland, MA, USA.

Newton, I. 2003. The speciation and biogeography of birds. Recherche. Academic Press, London.

Noivo, C., and J. Jara. 2007. First records of breeding Glossy Ibis Plegadis falcinellus in Portugal. Anuario Ornitologico 5:133-135.

Oro, D., and R. Pradel. 2000. Determinants of local recruitment in a growing colony of Audouin's gull. Journal of Animal Ecology 69:119-132.

Oro, D., and G. D. Ruxton. 2001. The formation and growth of seabird colonies: Audouin's gull as a case study. Journal of Animal Ecology 70:527-535.

Peery, M., B. Becker, and S. Beissinger. 2006. Combining demographic and count-based approaches to identify source-sink dynamics of a threatened seabird. Ecological Applications 16:1516-1528.

Phillips, B. 2009. The evolution of growth rates on an expanding range edge. Biology Letters 5:802-804.

Porter, J., and J. Coulson. 1987. Long-term changes in recruitment to the breeding group, and the quality of recruits at a Kittiwake Rissa tridactyla colony. Journal of Animal Ecology 56:675-689.

Pradel, R. 2005. Multievent: an extension of multistate capturerecapture models to uncertain states. Biometrics 61:442-447.

Pujol, G., B. Iooss, A. Janon, L. Gilquin, L. Le Gratiet and P. Lemaitre. 2014. Package 'sensitivity': Sensitivity Analysis. R. package version 1.9. http://CRAN.R-project.org/package $=$ sensitivity.

Ramo, C., E. Aguilera, J. Figuerola, M. Mañez, and A. J. Green. 2013. Long-term population trends of colonial wading birds breeding in Doñana (SW Spain) in relation to environmental and anthropogenic factors. Ardeola 60:305-326.

Rouan, L., R. Pradel, and R. Choquet. 2009. Program E-SURGE: a software application for fitting multievent models. Pages 845-865 in D. L. Thomson, E. G. Cooch and M. J. Conroy, editors. Series: environmental and ecological statistics. Springer, Boston, MA, USA.

Sæther, S., and Ø. Bakke. 2000. Avian life history variation and contribution of demographic traits to the population growth rate. Ecology 81:642-653.

Santoro, S., M. Mañez, A. J. Green, and J. Figuerola. 2010. Formation and growth of a heronry in a managed wetland in Doñana, southwest Spain. Bird Study 57:515-524.

Santoro, S., A. J. Green, and J. Figuerola. 2013. Environmental instability as a motor for dispersal: a case study from a growing population of glossy ibis. PLoS One 8:e82983.

Santoro, S., A. J. Green, J. R. Speakman and J. Figuerola. 2015. Facultative and non-facultative sex ratio adjustments in a dimorphic bird species. Oikos 124:1215-1224. doi: 10.1111/ oik.01889.

Sanz-Aguilar, A., G. Tavecchia, M. Genovart, J. M. Igual, D. Oro, L. Rouan, and R. Pradel. 2011. Studying the reproductive skipping behavior in long-lived birds by adding nest inspection to individual based data. Ecological Applications (21):555-564.

Schaub, M., O. Gimenez, B. R. Schmidt, and R. Pradel. 2004. Estimating survival and temporary emigration in the multistate capture-recapture framework. Ecology 85:2107-2113.

Skalski, J. R., A. Hoffmann and S. G. Smith. 1993. Testing the significance of individual-and cohort-level covariates in animal survival studies. Pages 9-28 in J. D. Lebreton, and P. M. North, editors. Marked individuals in the study of bird population. Birkhauser Verlag, Basel.

Stamps, J. 1988. Conspecific attraction and aggregation in territorial species. The American Naturalist 131:329-347.

Stearns, S. C. 1992. The evolution of life histories. Oxford University Press, Oxford.

Stubben, C. and B. Milligan. 2007. Estimating and Analyzing Demographic Models Using the popbio Package in R. Journal of Statistical Software 22.

Tavecchia, G., C. Viedma, A. Martínez-Abraín, M. A. Bartolomé, J. A. Gómez, and D. Oro. 2009. Maximizing re-introduction success: assessing the immediate cost of release in a threatened waterfowl. Biological Conservation 142:3005-3012.

Tims, J., I. Nisbet, M. Friar, C. Mostello, and J. Hatch. 2004. Characteristics and performance of common terns in old and newly established colonies. Waterbirds 27:321-332.

Valone, T. 1989. Group foraging, public information, and patch estimation. Oikos 56:357-363.

Van Groenendael, J., H. de Kroon, and H. Caswell. 1988. Projection matrices in population biology. Trends in Ecology \& Evolution 3:264.

Williams, B. 1975. Growth rate and nesting aspects for the Glossy Ibis in Virginia. Raven 46:35-51.

\section{SUPPORTING INFORMATION}

Additional supporting information may be found in the online version of this article at http://onlinelibrary.wiley.com/ doi/10.1890/14-2462.1/suppinfo 